\title{
Critical Success Factors in Project Management - Theoretical and Practical Aspects
}

\author{
Assist. Prof. PhD Borislava Galabova \\ University of Mining and Geology "St. Ivan Rilski” \\ borislavab.galabova@gmail.com
}

\begin{abstract}
This paper is dedicated on the critical success factors in project management. Different aspects of the question are analyzed - both theoretical and applied. The projects that are implemented in business organizations are the main focus. The aim is to seek, analyze and summarize various factors that are the most relevant for successful completion and final effect of the project - economic, technical, technological and social. Some adequate approaches and practices for reaching the intended project objective are searched for based on a study of theoretical positions, summary of current data and reports on the results of various projects. In the framework of this study is supported the thesis that there is a certain combination of critical success factors in the implementation of projects that have a decisive impact on the project process and its final result. For this reason, the good knowledge and effective management of these factors and their impact are confirmed as two of the main prerequisites for achieving success in the realization process.
\end{abstract}

Keywords: critical success factors (CSFs), project management, project, business organization

JEL Code: M210, M200; doi:10.36997/IJUSV-ESS/2019.8.3.47

\section{Въведение}

Проектният подход за решаване на конкретни теоретични и практически проблеми и въпроси доказва своята полезност и приложимост в хода на стопанското развитие. В исторически план като едни от най-големите и сложни за времето си проекти могат да се посочат Египетските пирамиди, Колизеумът, Александрийският фар и Великата китайска стена. В по-съвременен, през XX и XXI в. започват да се реализират сложни, скъпоструващи и новаторски проекти. Такива са и т.нар. „мега проекти“, сред които изграждането на Панамския канал (Панама, 1904-1914), Международната космическа станция (1998-2011), ВЕЦ „Хувър Дам“ (САЩ, 1931-1936), Тунелът под Ламанша (Франция-Великобритания, 1987-1994), Еърбъс А380 (1994-2005), Проект „Аполо“ (САЩ, 1961-1972).

През последните десетилетия ставаме свидетели на бурно развитие на индустрията, технологиите, иновационната, научно-техническа и развойна дейност. То става катализатор за разработването и изпълнението на все повече нови проекти във всички области на целенасочената дейност. Тези сложни по рода си начинания са с разнороден характер, цели и задачи. Те се различават по своя обхват, необходими ресурси, качество и време на реализация. Макар разликите да са осезаеми, общото между тях е, че чрез изпълнението им се преследва постигане на ясно дефиниран краен резултат - продукт на проекта. В този смисъл логичният стремеж на ръководителя и членовете на проектния екип по време на целия процес е насочен към това този резултат да бъде постигнат в предвидените ресурсни, времеви, количествени и качествени рамки.

Настоящата практика на управлението на проекти налага тьрсенето на отговор на някои важни въпроси с оглед получаването на по-добри икономически и социални резултати от практическата реализация на проектни начинания. Така например, защо една значителна част от проектите се провалят или не постигат предварително зададената цел в определената бюджетна и времева рамка? Могат ли да се изведат и обобщят определени критични фактори за успех, имащи ключова роля за развитието на проекта от началната до крайната му точка? Как да се повиши ефективността при управлението на проекти, като се спестят ресурси и 
време? От тези теми продължават да се интересуват широк кръг от специалисти - не само предприемачи и икономисти, но и инженери, общественици и политици.

На тази основа внимателният анализ на теорията и примерите от бизнес практиката дава възможност да се направят изводи и да се очертаят някои насоки. Чрез прилагането им следва да се достигне до по-висока ефективност и ефикасност и вследствие до по-добри резултати. Намирането на еднозначни отговори на поставените въпроси е трудна задача. Въпреки това процесът на тяхното търсене и използването на потенциалните намерени решения е ключов за по-успешната проектна реализация.

\section{1. Методическа рамка на изследването}

Обект на настоящото проучване са критичните фактори за успех при изпълнение на проектни начинания. „Critical Success Factors” (CSFs) е понятие, което се използва в системата от знания за управление на проекти. C него се обозначават дейностите, които трябва да бъдат изпълнени според най-високите стандарти, за да се достигне целта на проекта. Като CSFs могат да се приемат и онези важни параметри, които имат решаващо влияние върху резултата на проекта и по тази причина следва да са обект на внимателно управление. Основният фокус на проучването е насочен към проектите, които се изпълняват в рамките на бизнес организациите, чиято основна дейност е в сферата на индустрията. Това ограничение се поставя предвид значението на организациите с бизнес насоченост и тяхната дейност за икономическото развитие и растеж и към проектите, реализирани за получаване преимуществено на икономически ползи. Целта е да се потьрсят, анализират и обобщят различни дейности и респективно фактори, които имат най-голямо значение за успешния завършек и крайните ефекти от проекта - икономически, технически, технологични и социални. За проучването се използват методите на анализа и синтеза, индукцията и дедукцията, абстракцията и обобщението, наблюдението, аналогията и обработката на данни. Използва се широк изследователски инструментариум, който да позволи верифицирането на издигнатите хипотези. Въз основа на проучване на теоретични постановки, международни доклади за резултатите от различни проекти и обобщаване на актуални данни се търсят адекватни подходи и практики за постигане на добър завършек при подобни комплексни начинания. Основната теза е, че съществува определена комбинация от критични фактори за успех при реализацията на проекти, която има определящо влияние върху проектния процес и неговия краен резултат. По тази причина доброто познаване и ефективно управление на тези фактори и тяхното въздействие са две от основните предпоставки за постигане на успех при реализацията. Обратното, пренебрегването им и неефективното управление могат да доведат до провал или частично изпълнение на проекта.

\section{2. Основни характеристики на проекта и фактори, влияещи върху неговото управление}

Научното направление, станало известно като управление на проекти, се заражда и започва да се развива преди около 60-70 години. Оттогава и до днес значителна част от новите начинания в рамките на бизнес организациите се предприемат и изпълняват под формата на проекти. В хода на последните десетилетия проектите се превръщат в неизбежен компонент на съвременната бизнес практика, а научното направление, посветено на тяхното управление, започва да представлява интерес за широк кръг от специалисти. Основна причина за този интерес бе значимостта на проектните начинания и тяхната роля за икономическото развитие. Ето защо нарасна и стремежът към задълбочаване на познанията по въпроса как те да бъдат ефективно ръководени в условията на голяма динамика и неопределеност на околната среда. Осигуряването на конкурентоспособност и висока 
производителност изискват внимателен анализ на предпоставките и бариерите, които съпьтстват всеки проект. Те следва да бъдат определени и проучени, независимо дали биха попречили на успешното развитие на проекта или биха го стимулирали. Уточняването и подлагането на анализ на характеристиките на едно проектно начинание позволява по-лесно да се откроят голяма част от факторите, които имат определено влияние върху проектния процес и резултат. На тази база могат да се потърсят онези от тях, които попадат сред найзначимите.

Всеки проект е комплексно начинание, чиито успех е в пряка зависимост от редица фактори. Една част от тях са вътрешни за организацията, а друга са външни за нея. Факторната обусловеност произтича от състоянието и характера на средата, в която организацията оперира. Ето защо в днешните стопански условия остава актуален въпросът кои са ключовите фактори, който водят проектното начинание към успех и кои са онези, които го провалят. Правилната преценка на тези фактори и на тяхното позитивно или негативно влияние са в основата на проектния успех. В широк смисъл един проект може да се квалифицира като успешен, само ако зададената крайна цел е постигната. В по-тесен обаче това трябва да се случи в предварително зададената рамка за обхват, време, разходи и качество, като основни негови параметри. Проектният успех означава сьщо, че резултатът удовлетворява потребностите и очакванията на клиента/потребителя, които ще бъдат негови ползватели. Ако тези обстоятелства не са налице, не може да се твърди, че един проект е успешно завършен. На практика той може да се счита за неуспешен, когато заложената цел не е постигната в рамките на триъгълника време - разходи - качество или не е постиганата въобще. Обратното, проектът е успешен, когато тази цел е постигната при съответните първоначално приети параметри.

Провальт на всеки проект е свързан с преки и косвени икономически загуби за организацията, която го реализира. Според проучване на Project Management Institute (PMI) бизнес организациите губят около средно 109 млн. \$ на всеки 1 млрд. \$, инвестирани в проекти и програми (PMI, 2014). В практически план лошите проекти костват много финансови средства, което налага адекватно планиране и организиране, за да се избегне възможността от провал. Според прогнозни анализи на The Standish Group 31\% от проектите в бизнес организациите въобще няма да бъдат завършени, а 52,7\% ще струват два пъти повече от планираното. Съгласно проучвания на KPMG, 85\% от проектите надхвърлят времето за изпълнение с 1/3 или повече, а 9,9\% от всеки инвестиран долар се губи в резултат на недобро проектно изпълнение. Посочените резултати от международни изследвания са показателни, че провалът или частичното проектно изпълнение водят след себе си сериозни загуби на финансов, трудов и времеви ресурс и поставят под въпрос организационното развитие.

Всеки проект се отличава с уникалност и неповтаряемост и с определена специфика, свързана с конкретната сфера на дейност. Нито един проект не е пълно повторение на друг. Следователно и процесът на управление има свои особености, въпреки че се подчинява на обща методическа рамка. В основата на проектната концепция е заложен замисъльт за решаване на определен проблем и конкретната идея, в която има новаторство, иновация, стремеж към усъвършенстване и модернизация. Всеки проект се отличава и с известна доза новост. Оттам произтича и рисковата му природа и необходимостта от управление на риска. В този смисъл познаването на критичните фактори за успех подобрява перспективите за реализацията на такова сложно начинание. Това е особено важно, тъй като проектьт се развива в условията не само на риск, но и на неопределеност и ограниченост на ресурсите. В хода на неговата подготовка могат да се идентифицират и дефинират редица групи фактори, които да имат позитивно или негативно влияние върху целия процес. Тези фактори 
обикновено имат своето по-малко или по-голямо значение от началната до крайната точка на проекта. Внимателният им анализ е необходимо условие за постигане на задоволителен резултат, който да съвпада с предварителните очаквания и задания. Неизпълнението на целта означава, че проектьт не може да се квалифицира като успешен. Според Rockart (1982) например, за да си осигури бъдещ успех, организацията трябва да идентифицира критичните в съответния стопански отрасъл фактори. Това е онази съвкупност от фактори, която е свързана с постигането на удовлетворителен краен резултат. Управлението на проекти е област от знания, която осветлява именно тези аспекти на процеса на реализация на проекта - кои фактори, комбинации от фактори и добри практики по отношение на определени проектни параметри са от критична важност за успеха. Последното е от стратегическо значение за добрия и навременен ход на всеки проект.

Проектьт е свързан с целенасочени, систематизирани и координирани в конкретно направление усилия. Във всеки проект са вложени значителни ресурси и време. Затова от обществено-икономическа гледна точка е важно да не се допуска провал или само частично изпълнение. В тази връзка изследователите по темата се насочват към внимателно проучване на редица выпроси. Така например, какво различава успешните от неуспешните проекти? Защо една значителна част от проектите се провалят и къде следва да се потърсят причините за провала? Кои са предпоставките за това проектьт да се увенчае с успех и кои са заплахите за неговата реализация? Съществува ли определена комбинация от критични фактори, които могат сериозно да повлияят върху проектния процес и резултат? Валидна ли е тя за различни по вид, големина и характер проекти? Имайки предвид тези направления, уточняването на критичните фактори за успех се явява способ за приоритизиране на дейностите и задачите по степен на значимост и по време на изпълнение в проектния план. Това би допринесло за постигането на повече яснота и конкретизация, както и за по-голяма подреденост и синхрон между отделните цели, дейности и задачи в проектната структура, тъй като структурираният и целенасочен подход е особено важен в процеса на управление на проекти. В този смисъл като критични фактори могат да се определят онези проектни елементи и дейности, които са базисни за изпълняване на поставената главна мисия и цел. Те изискват специално внимание, защото тяхното неглижиране може да доведе проекта до провал или нежелан резултат.

Внимателният анализ изисква пьрво да се изясни каква част от проектите се провалят. Този въпрос е от особено значение за по-мащабните проекти, които по правило са и подълготрайни. Според проведени от The Standish Group изследвания, през последните пет години по-малко от една трета от проектите са изпълнени успешно. Успехът на проекта се дефинира като реализиране на поставената цел при определения бюджет и времева рамка, а провален е онзи проект, който е само частично изпълнен в бюджетните и времеви ограничения или не е изпълнен изобщо. Позовавайки се на това, значителна част от бизнес организациите в световен мащаб регистрират, че $70 \%$ от техните проекти се провалят, защото не успяват да бъдат изпълнени на практика, надхвърлят бюджета или закъсняват спрямо установения график. Отчетеният дял е твърде висок и е показателен за сериозната необходимост от анализ на проблема и набелязване на подходи за преодоляване на риска от възможен провал или частично изпълнение. В допълнение, едва $30 \%$ от проектите са реализирани според първоначално заложените базисни параметри. Тези данни свидетелстват, че често реалното изпълнение на проектите не се припокрива с планираното. Според проучване на РМІ само 64\% от проектите постигат точно целите си (PMI, 2015). Успоредно с това $70 \%$ от бизнес организациите докладват, че поне един от проектите им през изминалата година се е провалил (KPMG, 2010), което очертава ролята на идентифицирането и управлението на критичните фактори за успех. Същевременно организациите, отчели високи икономичеки постижения, успяват да реализират $89 \%$ от всички изпълнявани от тях проекти, 
докато тези с по-малки - едва 36\% (PMI, 2014). От посочените данни е видно, че в настоящата динамично развиваща се икономическа среда част от бизнес организациите не успяват да реализират успешно своите проекти, така както те са били планирани или нямат капацитет да ги изпълнят въобще. Част от проектите не постигат целите си, а получените резултати не удовлетворяват заинтересованите страни, което също означава, че не са успешни. Причините и предпоставките за тези неудовлетворителни резултати следва да са обект на анализ.

Всеки проект крие значителни рискове въобще да не бъде завършен, резултатът силно да се различава от предварителните очаквания или проектьт да не се движи точно по оста обхват - време - разходи - качество. Независимо от своето естество, проектьт е сфера на дейност, която има силно рисков характер. Той може да се обясни с невъзможността с точност да се предвиди както резултата, така и начина на протичане на самия процес. Нерядко планираното и прогнозираното се отличава от реално постигнатото. На първо място, рискът произтича от несигурността и неопределеността на средата и влиянието на външните фактори върху самата организация и нейната дейност. На второ място, той се увеличава от невъзможността да се контролират напълно и навременно всички процеси вътре в самата организация и взаимодействията между компонентите на вътрешната среда. Крайният резултат от проекта ще бъде известен в края на по-кратък или по-дълъг период, т.е. той е отложен във времето. Дали въобще ще бъде достигнат и кога също е въпрос без стопроцентов отговор. Налице е следната зависимост: колкото по-отдалечен се очаква да е, толкова по-висок е и рискът. Рисковата природа на проектното начинание е само една от предпоставките да се потьрсят и проучат критичните фактори за успех. Другата причина се крие в стремежа да се увеличи ефективността и да се подобрят крайните резултати. Повисока ефективност и резултатност са постижими именно чрез по-доброто познаване на факторната обусловеност на проектното начинание и следенето на хода на проекта в това отношение. Така темата за проектния успех и факторите, които го обуславят остава ключова, тъй като цялата концепция за управление на проекти е заложена в нейната основа. Тя е все така актуална и дискусионна, като продължава да е обект на интерес в контекста на цялостната методология за управление на проекти.

\section{3. Критичните фактори за успех и управлението на проекти}

Ефективността на дейността по управление на проекти изисква внимателна преценка и анализ на критичните за успеха на проекта фактори. За целта трябва да се направят три уточнения. Първо, макар да може да се обособи определена обща съвкупност от фактори, за всеки проект могат да се наблюдават определени особености. Второ, при по-сложни, специфични или дълготрайни проекти е възможно добавянето на допълнителни критични фактори, за да се получи цялостна и вярна картина. Трето, степента и силата на влияние на комплекса от критични фактори може да варира съобразно сферата на дейност, в която се изпълнява проекта, нейната конкретна насоченост и вида на самия проект.

Повечето изследователи по темата за критичните фактори за успех консолидират мненията си относно това, че съществува определен набор от променливи (фактори), които имат сериозно отражение върху процеса и резултата от проекта. Дискусионен обаче остава въпросът кои са тези фактори и доколко могат да са валидни за всеки проект. Измерването на тяхното влияние от статистическа гледна точка също е трудно, поради разнопосочното им въздействие и натрупването му, както и поради корелацията между отделните фактори.

Pinto, Slevin и Prescott първи правят проучване по темата през 80-те години на миналия век, когато управлението на проекти вече сериозно навлиза като способ за постигане на организационни цели. Техният модел за успех на проекта се изразява чрез 
четири основни параметьра: време, разходи, изпълнение и клиентска удовлетвореност. Pinto and Slevin (1988) идентифицират няколко дейности и фактори, свързани с успешното изпьлнение на различни видове проекти. Като такива те посочват плана и графика, клиентското одобрение, мониторинга и обратната връзка, комуникацията, профила на ръководителя и процеса по разрешаване на проблеми. Така подходът, свързан с критичните фактори за успех започва да се налага в теорията и практиката по управление на проекти.

Chan et al. (2004) твърдят, че критичните за успеха на проекта фактори могат да се групират в пет основни категории. Те включват:

- фактори, ориентирани към човешките отношения;

- фактори, пряко свързани със самия проект;

- фактори, свързани с процедурите;

- фактори, свързани с управлението;

- фактори, свързани с външната среда.

Фактори от една група могат да влияят върху фактори от друга и обратното, като се получава синергетичен ефект. Възможно е също така тяхното въздействие да се усилва или да отслабва вследствие от комбинираното им влияние. Целта на проекта следва да е пряко свързана с очакванията на всички заинтересовани страни и може да се индентифицира с тях, въпреки че е възможно те да се различават (Chan et al., 2004). Очакванията трябва да се пресичат поне в една допирна точка, която да бъде формулирана като главна цел.

Позовавайки се на тези основни теоретични постановки, през 2019 г. бе извършено анкетно проучване сред двадесет мениджъри на проекти в бизнес организации, опериращи на територията на България. Основна негова цел бе идентифицирането и оценката на потенциални критични фактори за успех за изпълняваните от съответната организация проекти и влиянието им върху процеса и крайните резултати. При разработването и разпространяването на анкетата сред заинтересованите организации бяха поставени следните ограничителни условия, които да осигурят по-голяма полезност и обективност на проучването:

- организацията да е реализирала поне два различни проекта през последните десет години;

- за управлението на изпълняваните проекти организацията да е сформирала собствено обособено звено/отдел за управление на проекта/ите и да не е използвала услугите на специализирани в сферата на управлението на проекти консултантски организации, за да управлява изпълнявания/те проект/и;

- основната дейност на организацията да е в сферата на индустрията;

- срокът на изпълнения/те проект/и да е не-по малък от 6 месеца, а бюджетьт да е не по-мальк от 10000 лв.

Обобщаването на мненията на попълнилите анкетната карта ръководители на проекти в съответните организации показват, че сред най-често посочваните причини за провал или частично изпълнение са:

- смяната на приоритетите в стратегическата рамка на организацията и изменението на цялостната стратегия, което води до съответни промени - отпадане/промяна на текущ проект, заместването му или допълването му с друг и др.;

- нереалистичните, неточни или непрецизирани първоначални изисквания, допускания и ограничения, които предизвикват несъответствия и необходимост от корекции по време на етапите на реализация;

- промяната на организационните цели и задачи, която влияе върху планирания/изпълнявания проект и тьрсения резултат;

• неидентифицираните или неправилно идентифицираните рискове и неефективното 
управление на риска;

- неидентифицираните или неправилно идентифицираните възможности за решаване на проблема, който следва да се преодолее чрез проектната реализация;

- лошата комуникация между членовете на екипа/ите или с вътрешните и външни заинтересовани страни;

- липсата на подкрепа от страна на спонсора и/или ръководителя на организацията;

- нереалистичните или неточни финансово-икономически оценки и прогнози, които повлияват върху бюджета на проекта;

- неефективното управление на промяната при изменения във вътрешната или външната за проекта среда;

- ограничените количествено и/или качествено ресурси, несъответстващи на поставената цел и обхват на проекта;

- ограниченото време за изпълнение на проекта, което води до проблеми при изготвяне на график и неговото следване;

- недостатъчният капацитет (в т.ч. знания, умения и компетенции на екипа) за изпълнение и управление на проекта;

Обобщаването на мненията от попълнените анкетни карти показва, че общо 17 от анкетираните 20 рьководители на проекти посочват, че при изпълнваните проекти могат да се обособят няколко важни фактора или комплекс от такива, които имат определящо значение за изпълнението и резултата от проекта. Анкетираните потвърждават, че група фактори са оказали позитивно и/или негативно влияние върху процеса на управление и резултата от него, като са допринесли пряко за успешното/неуспешното завършване. Общо 8 от анкетираните 20 ръководители посочват, че в досегашната си практика в организацията се е случвало да подценят значението на един или повече от тези фактори и тяхното влияние върху проекта, което е довело до забавяне в предвидения график, увеличаване на бюджета, необходимост от намаляване на обхвата на проекта или промяна на очаквания краен продукт-резултат. Общо 15 от анкетираните 20 рьководители заявяват, че идентифицирането, познаването и управляването на критичните фактори за съответния проект, развиващ се в рамките на конкретната организация, е базисно условие за ефективно управление на проекта и получаване на планирания резултат.

\section{Заключение}

Настоящата практика по управление на проекти налага търсенето на отговор на някои важни въпроси с оглед получаване на по-добри икономически и социални резултати от реализацията на проектни начинания. Внимателният анализ на теорията и примерите от реалния бизнес дават възможност да се направят изводи и да се очертаят насоки за предприемане на действия. Чрез следването им може да се достигне до по-висока ефективност и ефикасност, а оттам и до по-добри крайни резултати. Именно ефективността на дейността по управление на проекти изисква внимателна преценка и анализ на критичните за успеха на проекта фактори.

Направеното за целите на изследването анкетно проучване сред представителите на бизнеса дава основание да се потвърди, че е възможно обособяването на определена съвкупност от критични фактори за успех при реализацията на проектни начинания, която има определящо влияние върху проектния процес и неговия краен резултат. Доброто познаване на тези фактори и управление на тяхното въздействие са две от основните предпоставки за постигане на успех в хода на реализацията. Обратното, пренебрегването и неефективното им управление създават предпоставки за провал или частично изпълнение на проекта. Това потвърждава значението на критичните фактори за успех и ролята им в 
добрата практика по управление на проекти.

\section{References}

1. Alias, Z., Zawawi, E.M.A., Yusof, K., Aris, N.M. (2014) Determing Critical Succes Factors of Project Management Practice: A conceptual framework. Procedia - Social and Behavioral Sciences 153, pp. $61-69$

2. Chan, A.P.C., Ho, D.C.K., Tam, C.M. (2001) Design and Build project success factors; Multivariate analysis. Journal of Construction Engineering Management, 127(2), pp. 93-100

3. Chan, A.P.C., Scott, D., Chan, A.P.L. (2004) Factors affecting the success of a construction project. Journal of Construction Engineering Management, 130(1), pp. 153-155

4. Chan, D.W.M., Kumaraswamy, M.M. (2002) Compressing construction durations: Lessons learned from Hong Kong building projects. International Journal of Project Management. 20(1), pp. 23-35

5. KPMG New Zealand, (2010) Project Management Survey 2010

6. Muler, R., Jugdev, K. (2012) Critical Success Factors in projects: Pinto, Slevin, and Prescott the elucidation of project success. International Journal of Managing Projects in Business, vol. 5, issue 4, pp. 757-775

7. Obadia, B. (2018) Why Project Fail?. Project Management Journal, Vol. 1 (1000), 7 July 2018

8. PMI, (2018) PMI's Pulse of the Profession, Success in Disruptive Times

9. PMI, (2015) Pulse of the Profession 2015: Capturing the Value of Project Management 2015

10. PMI, (2014) Pulse of the Profession 2014 - The High Cost of Low Performance

11. The Standish Group, Official site, Available at: https://www.standishgroup.com/about [Accessed 10/09/2019]. 